
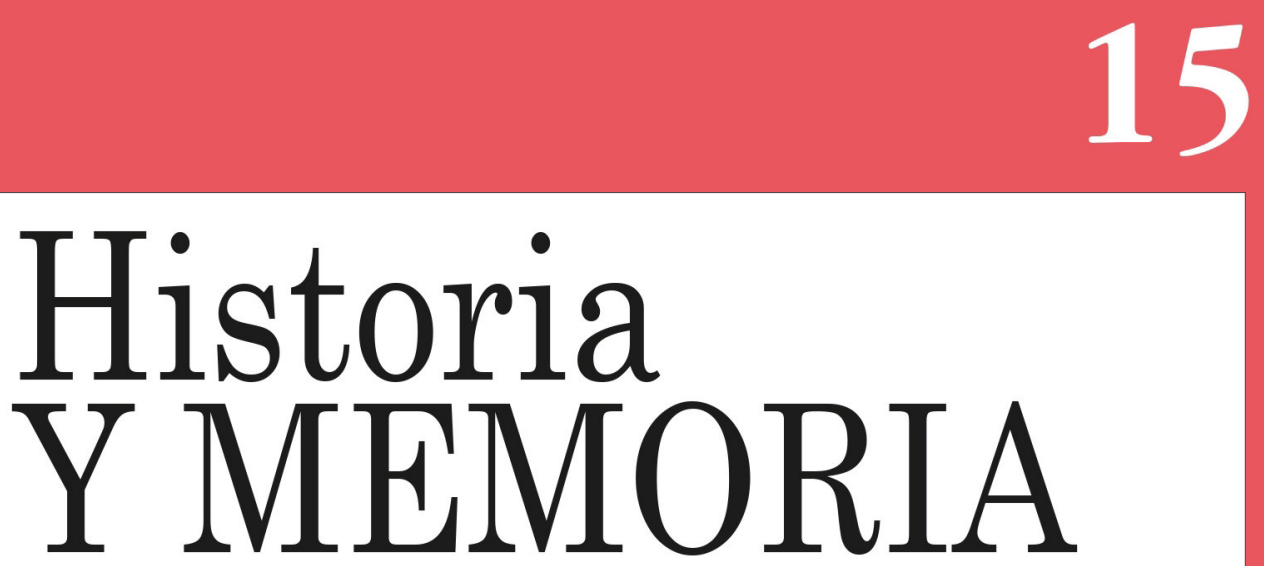

ISSN: 2027-5137 Julio - Diciembre, Año 2017 - Tunja, Colombia

Pintores en el esplendor de Tunja: nombres de artífices para salir del anonimato (siglos XVI y XVII)

https://doi.org/10.19053/20275137.n15.2017.5538

Laura Liliana Vargas Murcia orcid.org/0000-0001-8411-3085

Páginas: 49-72






\title{
Pintores en el esplendor de Tunja: nombres de artífices para salir del anonimato (siglos XVI y XVII)*
}

\author{
Laura Liliana Vargas Murcia ${ }^{1}$ \\ Universidad Nacional de Colombia
}

Recepción: 31/10/2016

Evaluación: 11/01/2017

Aprobación: 08/03/2017

Artículo de Investigación e Innovación.

doi) https://doi.org/10.19053/20275137.n15.2017.5538

\section{Resumen}

Tunja se ha destacado dentro del Nuevo Reino de Granada como una de las ciudades más ricas en cuanto a presencia de pintura durante las últimas décadas del siglo XVI y la primera mitad del XVII; sus pintores no solamente tuvieron proyección en esta ciudad sino en el resto de la Provincia, siendo las iglesias y museos boyacenses contenedores de imágenes que fueron elementos esenciales en la doctrina de indios. Las obras murales civiles tunjanas han sido objeto de estudios centrados principalmente en su interpretación y menos en las identidades

* El presente artículo se enmarca dentro de la investigación «Arte en el Nuevo Reino de Granada». [Agradezco al antropólogo Jorge Augusto Gamboa Mendoza por sus indicaciones sobre documentos e información relacionada con el periodo estudiado].

1 Doctora en Historia del Arte y Gestión Cultural en el Mundo Hispánico (Universidad Pablo de Olavide, Sevilla). Integrante del grupo de investigación «Estudios históricos y artísticos de bienes culturales» de la Universidad Nacional de Colombia. Línea de investigación: Arte colonial del Nuevo Reino de Granada. Publicaciones recientes: «Construcción, circulación y uso de una imagen. El caso de la Azucena de Quito", en Visiones renovadas del Barroco iberoamericano, ed. María del Pilar López y Fernando Quiles. (Sevilla: Universidad Pablo de Olavide, Alcaldía Mayor de Bogotá, Universidad Nacional de Colombia, y Universidad de los Andes, 2016) 134-145. «Dos regalos para Carlos IV y María Luisa de Parma: un hermoso loro y un mozo gigante, la historia de dos pinturas neogranadinas en el Archivo General de Simancas», en Arte y patrimonio en Iberoamérica. Tráficos transoceánicos, ed. Inmaculada Rodríguez Moya, María de los Ángeles Fernández Valle y Carmen López Calderón. (Castellón: Universitat Jaume I, 2016) 255-267. \ lauralilivm@gmail.com (iD) orcid.org/0000-0001-8411-3085 
de sus artífices, mientras que en lo tocante a pintura de caballete, la figura de Angelino Medoro en cierta medida ha opacado el nombre de otros artistas que contribuyeron a hacer de Tunja una de las urbes más representativas del manierismo y el renacimiento en la América española. El presente artículo reúne los nombres de algunos de los pintores activos en este periodo y da algunas noticias sobre sus vidas y producción, buscando el reconocimiento de estos personajes que en los últimos años han ido saliendo del anonimato. La búsqueda de información tuvo como punto de partida las investigaciones de Magdalena Corradine Mora sobre los habitantes de la ciudad de Tunja en las primeras décadas del siglo XVII y la búsqueda de información en el Archivo Histórico Regional de Boyacá. Al llamar la atención sobre estos artistas, se espera que en un futuro se inicie un trabajo de identificación de sus obras, su investigación, conservación y difusión, ya que este patrimonio que no siempre está en las condiciones ideales, ni es percibido y valorado como merece.

Palabras clave: Nuevo Reino de Granada, Tunja, pintores, pintura colonial, arte virreinal.

\section{Painters in the Splendor of Tunja: Naming Unrecognized Artists to Bring them out of Anonymity (XVI and XVII centuries)}

\section{Summary}

Tunja has stood out as one of the riches cities of New Kingdom of Granada, regarding the presence of painting in the last decades of the XVI century and the first half of the XVIIth. Its painters were of importance not only in this city but in the rest of the Province as well, with the churches and museums of Boyacá containing images that were essential elements in the indoctrination of indigenous communities. Civil mural works of art in Tunja have been an object of study mostly for their interpretation, and less regarding the identities of their makers. As far as easel painting, Angelino Medoro eclipsed the names of other artists who contributed to making Tunja one the the most representative cities of the Mannerism and 
Renaissance of Hispanic America. This article presents the names of some of the active painters of this period, their lives and production, seeking the recognition of these characters, whose names have been brought out of anonymity in the latest years. The starting point for the information search was the research of Magdalena Corradine Mora on the inhabitants of Tunja in the first decades of the XVII century, and the search for information in the Boyacá Regional Historical Archive. In calling attention upon these artists, we hope that, in the future, the identification of their works may be initiated as well as the research, conservation and dissemination of these works, due to the fact that this heritage is not always in ideal conditions, nor is it perceived and valued as is deserved.

Key words: New Kingdom of Granada, Tunja, painters, colonial painting, viceroyal art.

\section{Peintres de l'apogée de Tunja: des noms d'artistes pour sortir de l'anonymat (XVI ${ }^{\mathrm{e}}-\mathrm{XVII}{ }^{\mathrm{e}}$ siècles)}

\section{Résumé}

Du point de vue de la peinture, Tunja était l'une des villes les plus riches du Nouveau Royaume de Grenade de la fin du XVI et la première moitié du XVII ${ }^{\mathrm{e}}$ siècles. Ses peintres ont dépassé le cadre de la cité pour embrasser toute la scène provinciale. C'est ainsi que les églises et les musées du Département de Boyacá recèlent des images qui ont été autrefois des éléments essentiels de l'évangélisation des Indiens. Jusqu'à présent les fresques civils de Tunja ont fait l'objet d'études centrées plutôt dans leur interprétation que dans l'identité de leurs auteurs, alors que la figure d'Angelino Medoro a porté ombrage aux autres peintres de chevalet qui ont contribué à faire de la ville l'un des centres du maniérisme et de la Renaissance dans l'Amérique espagnole. Cet article réunit le nom de quelques-uns des peintres actifs pendant la période et donne quelques informations à propos de leurs vies et de leurs œuvres, cherchant ainsi à faire émerger ces personnages qui commencent à sortir de l'anonymat depuis quelques années. La recherche a pour point de départ les travaux de Magdalena 
Corradine Mora à propos des habitants de la cité pendant les premières décennies du XVII ${ }^{\mathrm{e}}$ siècle, enrichis avec des documents provenant des Archives Historiques Régionales de Boyaca. On attire l'attention sur ces artistes dans l'espoir qu'une d'identification systématique de leurs œuvres soit entreprise, ainsi que d'autres recherches et des travaux de restauration, car ce patrimoine ne se trouve pas toujours dans des conditions optimales de conservation.

Mots-clés: Nouveau Royaume de Grenade, Tunja, peintres, peinture coloniale, art de la vice-royauté.

\section{Introducción}

Hasta hace una década, la información con la que se contaba sobre pintores en la Tunja de mayor esplendor -las últimas décadas del siglo XVI y las primeras del XVII- se limitaban a lo escrito por Santiago Sebastián quien hizo mención a la labor de Angelino Medoro y Juan de Rojas en la pintura y el dorado de la capilla de los Mancipe en la Iglesia Mayor de Santiago ${ }^{2}$, y en la mención del pintor 'Otero', nombre que aparece en la pintura de la techumbre de la Casa de Juan de Castellanos, citado por José Miguel Morales Folguera ${ }^{3}$.

El trabajo de investigación documental realizado por Magdalena Corradine $e^{4}$ descubrió el nombre de los vecinos tunjanos de aquellos momentos, a partir del censo de 1620, del plano de la ciudad de 1623 y de una dedicada búsqueda en el Archivo Histórico Regional de Boyacá, arrojando valiosa información sobre los oficios por ellos desempeñados, entre los que hubo pintores, policromadores y doradores, de quienes

\footnotetext{
2 Santiago Sebastián, Estudios sobre el arte y la arquitectura coloniales en Colombia (Bogotá: Corporación La Candelaria y Convenio Andrés Bello, 2006), 76, 110, 198, 262, 349, 350, 367, 376 y 349. Citando:

«Testamento de Antonio Ruíz Mancipe» Tunja, 29 de julio de 1598, Archivo Histórico y Regional de Boyacá (AHRB), fondo Notaría 2, leg. 65, ff. 170r - 190v.

3 José Miguel Morales Folguera, Tunja, Atenas del Renacimiento en el Nuevo Reino de Granada (Málaga: Universidad de Málaga, 1998), 285 y 286.

4 Magdalena Corradine Mora, Vecinos y moradores de Tunja 1620-1623 (Tunja: Consejo editorial de autores boyacenses, 2009), 13, 14, 127, 137, 148, 162, 191, 189 y 197.
} 
ahora presentamos información útil para reconstruir algunos aspectos relacionados con su obra, vida y tejidos sociales para comprender mejor su forma de producción pictórica.

\section{Pintores, policromadores, escultores y doradores, vecinos de Tunja.}

El primer concierto de aprendizaje, en calidad de aprendiz de oficial, en la ciudad de Tunja, conocido hasta ahora es el celebrado entre Gonzalo Caravallo o Caraballo, oficial pintor, y Juan Recuero, quien también era ya pintor en el año $1587^{5}$. Es importante resaltar que para este año, Recuero ya contaba con conocimiento y experiencia, pues en 1590, al servir como testigo en el pleito entre el pintor Juan de Rojas y Antonio Jove, declaró haber sido aprendiz oficial de Rojas en el momento en el que hicieron las pinturas del Cabildo, alrededor del año $1582^{6}$; para el año en el que da testimonio, dijo tener más o menos 24 años, colaboró en la obra de Rojas para Jove cuando contaba con unos 16 años e inició su formación con Carvallo teniendo unos 21 años, lo que indica que nació hacia 1566. En el momento de firmar el contrato de aprendizaje, Recuero, no supo hacerlo por lo que firmó un testigo, según dice el concierto, lo que quiere decir que el conocimiento recibido lo había adquirido de manera oral y que no tenía la capacidad de leer tratados o de escribir la información recibida en la casa de su maestro o durante la ejecución de encargos. Otro detalle que revela este texto judicial es que junto a ellos trabajaban tres oficiales más cuyo nombre desconocemos pero que demuestra que poco a poco el oficio y por lo menos el taller y el nombre de Rojas como pintor se iba consolidando en Tunja. La demanda de Rojas a Jove se debió dar en un momento de apuro económico del pintor, pues en 1588 había hipotecado

5 «Concierto de aprendizaje de pintor entre Juan Recuero y Gonzalo Caravallo» Tunja, 1587, AHRB, fondo Notaría 2, leg. 41, ff. 222 rv. Transcrito en: Laura Liliana Vargas Murcia, Del pincel al papel: Fuentes para el estudio de la pintura en el Nuevo Reino de Granada (1552 -1813) (Bogotá: Instituto Colombiano de Antropología e Historia ICANH, 2012), 96-98.

6 «Pleito entre Juan de Rojas, pintor, y Antonio Jove, corregidor y justicia mayor de Tunja, por pago de pintura mural de la casa de cabildo" Tunja, 1590, Archivo General de la Nación (AGN), Sección Colonia, fondo Residencias de Boyacá, leg. 1, ff. 609r-610r. Transcrito en: Vargas Murcia, Del pincel..., 114-115. 
dos solares suyos como obligación de pago a Pedro Jovel, por varias mercaderías de las que no entra en detalle aparte de nombrar unas varas de paño, sumando todo 103 pesos y 7 tomines de oro fino ${ }^{7}$.

Pero Juan de Rojas no solamente fue pintor. En la carta de recibo de dote dada por Gaspar Arias e Isabel Rincón por su casamiento con su hija Isabel Arias Rincón, hecha en 1589, él mismo se reconoce como 'escultor de imaginería'. Con seguridad, se podría afirmar que su labor en la talla y policromía de imágenes se vio enriquecida por la observación de obras llegadas de la península producidas en los talleres de afamados maestros como Juan Bautista Vázquez «el viejo», Francisco de Ocampo, discípulos de Jerónimo Hernández, Gaspar del Águila, Juan de Oviedo o Diego López Bueno, entre otros, las cuales fueron encargadas para templos de la ciudad o de pueblos cercanos como Villa de Leyva, por habitantes de Tunja como Juan de Leguizamón, Isabel de Leguizamón o Juan de Porras Marquina ${ }^{9}$.

Pasando al otro pintor nombrado en el pleito citado, Juan Recuero, en su testamento de $1630^{10}$ dejó como voluntad ser enterrado en la Iglesia parroquial de Santiago. Durante su matrimonio con María de Ponte tuvo como hijos legítimos a Juan Martínez de Ponte, Francisca Recuero de Céspedes, Andrés Recuero, Lorenza de Ponte, Sebastián de Ponte, Joseph Recuero, Bartolomé Inclán, Augustina de Céspedes, Bárbola

\footnotetext{
7 «Obligación de pago de Juan de Rojas a Pedro Jovel,» Tunja, 1588, AHRB, fondo Notaría 2, leg. 44, tomo 2, ff. 354rv.

8 "Carta de recibo de dote a Juan de Rojas» Tunja, 1589, AHRB, fondo Notaría 2, leg. 44, tomo 2, ff. 267r-271r. Como dote Juan de Rojas recibió 800 pesos de oro de 20 quilates en joyas de oro (cadena de oro menuda, cruz de oro y esmeraldas y pinjantes de perlas, una lagartija de oro y esmeraldas, una sortija de esmeraldas, taza de plata dorada, jarros y cubilete de plata, 100 pesos de oro en 400 ovejas, 300 pesos de oro en la mitad de la casa y 200 pesos en ajuar y preseas de la casa (colchones, sábanas, almohadas, cama, camisas, zaragüelles, tocadores de ruan, pañuelos, paños de mano, gorgueras, tocas, escofiones, guerguetas, sayales y un manto).

9 Lázaro Gila Medina y Francisco J. Herrera García, «Escultores y esculturas en el Reino de la Nueva Granada (Colombia)", en La escultura del primer naturalismo en Andalucía e Hispanoamérica, coord. Lázaro Gila Medina (Madrid: Ministerio de Ciencia e Innovación, 2010), $491-548$.

10 «Testamento de Juan Recuero de Céspedes» Tunja, 1630, AHRB, Notaría 2, leg. 103, ff. $65 \mathrm{r}-68 \mathrm{r}$.
} 
Recuero y María de Ponte ${ }^{11}$, recordando como hijos difuntos a Diego Martínez de Ponte y a Margarita de Chinchilla; entre sus albaceas estaban Juan Martínez y Sebastián de Ponte, dos de sus hijos, quizás muy cercanos por haberse dedicado al oficio del padre, como se verá más adelante. En lo referente a su obra, declaró que debía a Juan, indio de Paipa, veinte pesos que le había dado por la hechura de un San Juan, los cuales recibió en géneros pero el contratante no quiso después la dicha hechura y dijo que la conmutaría en otra y nunca volvió a pedirla. Aunque Recuero dejaba deudas, sobre todo a mercaderes, también era propietario de doscientas cabezas de ovejas, casas y solares. En el manuscrito notarial dejó constancia de no saber leer ni escribir, por lo que no dejó registros de vales, pagos o deudas de su mano, situación de analfabetismo que evidenció desde que era un joven oficial y que nunca subsanó ${ }^{12}$.

De Recuero también sabemos que transmitió su oficio de pintor a su hijo Sebastián de Ponte, quien en su testamento de $1633^{13}$, se declaró 'policromador' pero además 'escultor'. Su madre fue María de Ponte, y ambos padres ya habían fallecido para tal año y estaban enterrados en la Iglesia Parroquial de Santiago, donde su hijo también pedía reposar al momento de su muerte. Las obras que aún tenía pendientes por hacer, y el dinero que se le adeudaba nos permiten ver que en los pueblos de indios de la Provincia de Tunja no había muchos artífices para la realización de bultos y tenían que encargarlos en la ciudad, así como también que los indígenas estaban interesados en tener imágenes religiosas, lo que denota su sentido de pertenencia al catolicismo ya entrado el siglo XVII.

11 Puede ser que la cantidad de hijos no permitiera a la familia una situación acomodada, como se puede percibir en la donación que Fabián Ponte le hace a su hermana María de Ponte, esposa de Juan Recuero, por estar "pobre y cargada de muchos hijos» en: «Donación de Fabián de Ponte a María de Ponte» Tunja, 1622, aunque el lomo del tomo indica año 1621-1622, AHRB, fondo Notaría 2, leg. 92, ff. $141 \mathrm{v}-142 \mathrm{v}$.

12 Existen otros documentos en los que se dan noticias sobre Juan Recuero, como la promesa firmada en 1597 para pagarle 60 pesos de oro corriente de 13 quilates en el plazo de un año a Cristóbal de Hormaza por unas mercancías. En: «Obligación de Juan Recuero,» Tunja, 21 de abril de 1597, AHRB, Notaría 2, leg.60, f. 167r.

13 «Testamento de Sebastián de Ponte» Tunja, 1633, AHRB, Notaría 2, leg. 106, t. 2, ff. 109v-111r. Transcrito en Vargas Murcia, Del pincel..., 182-185. 
Ponte había hecho tratos con indios de Pesca (un san Juan Bautista y un Niño Jesús), de Turmequé (un san Absalón), de Tobasía (un san Isidro), de Chivatá (un san Antonio de Padua), de Firavitoba y de Tunja (una lanza dorada, lo que indica su conocimiento en el arte del dorado), además de otras imágenes a personas que identifica en el manuscrito. Un dato relevante que contienen las últimas voluntades del policromador es que dejó a su hermano la responsabilidad de terminar las obras que debía y le heredó sus colores, oro y herramientas de su oficio, revelándonos su identidad: Juan Martínez de Ponte, nombre que se suma a esta lista de artistas activos en Tunja a principios del siglo XVII, y que ya había sido nombrado en el testamento de su padre Recuero como hijo legítimo y albacea. A juzgar por su testamento, Sebastián de Ponte, tuvo una situación acomodada como pintor, pues no declaró deudas y recordó ser el encargado de pagar el arrendamiento de las casas en las que vivían sus tías y que eran propiedad del Convento de Santo Domingo.

Un interesante documento es la compañía que formaron Recuero y Mateo Maldonado en 1593 para trabajar juntos como pintore ${ }^{14}$, durante dos años, en obras de pintura, que se entiende como mural y caballete, y pintura de bultos, es decir policromías; el concierto contiene las siguientes actividades a realizar por el oficial Maldonado bajo el mando de Recuero, comprometiéndose a hacerlas sin excusas: trabajo de las obras de pintura de pincel, guarnecerlas de bulto (tareas que divide el contrato en: dorado, encarnaciones y obras gruesas), asentar colores, dorar y labrar en lienzos y demás cosas anexas al oficio (no especificadas), y su ganancia sería de un tercio en obras de pintura y de un quinto en las de policromía de escultura, restando previamente a la ganancia principal los gastos en lienzos, colores 'y otros aderezos', así como el alquiler de casa, comida, vestido y calzado necesarios para la realización de los encargos; por su parte, Recuero le enseñaría lo concerniente al oficio de pintor. El joven Mateo ${ }^{15}$ afirmó tener entre 22 y 25

14 «Compañía entre Juan Recuero y Mateo Maldonado para ambos trabajar como pintores», Tunja, 15 de diciembre de 1593, AHRB, fondo Notaría Segunda, leg. 54, ff. 199r-201r. Ver Apéndice que acompaña este artículo.

15 En el concierto aparece como Mateo Maldonado y como Mateo de Castro. 
años al momento de su trato con Recuero, lo que indica que habría nacido alrededor de 1568 y 1571 . Se debe resaltar que actuó como testigo Sebastián de Ponte, el ya nombrado hijo de Juan Recuero.

La presencia de un pintor y escultor proveniente de la Provincia de Quito en Tunja llama la atención, se trata del indio pintor Andrés Guauque, natural de Cotocollao, quien testó en 1625 pero que no dejó información sobre el momento en el cual arribó a la ciudad. En el testamento pidió ser enterrado en la Iglesia de Santiago vestido con el hábito de San Francisco. Como era común en esta época, por el pago de sus obras recibía bienes, lo que se observa en la memoria de lo que se le adeuda: el capitán Becerra que residía en Rasgón le debía una mula cerrera buena por la hechura de un Cristo de bulto que le hizo, y Catalina Becerra, criada del capitán Becerra, un macho cerrero por la hechura de dos imágenes pequeñas y un Cristo. Entre sus propiedades enumeró un lienzo grande al temple de Nuestra Señora del Reposo y otro lienzo pequeño de la Oración del Huerto, uno de la Coronación de Nuestro Señor Jesucristo, otro de la Magdalena, una pintura del Descendimiento de la Cruz, un lienzo viejo de San Juan Bautista y otro lienzo de Nuestra Señora al óleo de media vara de alto, y según dijo, todos estaban por guarnecer. Entre los materiales de su oficio consideró pertinente nombrar en el documento notarial «siete libras de albayalde y los colores de mi oficio y dos libras de azul de Mérida y dos libras de cardenillo y los demás trastes del dicho oficio» ${ }^{16}$ y "toda la herramienta de escultoría, dos azuelas, sierras y otros hierros» ${ }^{17}$ que pidió se vendieran para pagar deudas. Este pintor estaba casado con Leonor de Reina, y para él y su mujer dispuso la fundación de una capellanía en la hermandad de Nuestra Señora de la Soledad que estaba fundada en la Iglesia mayor de esta ciudad, solicitando misas en honor de Santa Ana, San José, San Lino, Nuestra Señora, San Joaquín, San Agustín y San Francisco, y otra misa a la Pasión de Jesucristo en la Semana Santa. No tuvo hijos con su

16 «Testamento de Andrés Guauque, pintor», Tunja, 1625, AHRB, fondo Notaría 2, leg. 98 , f. $136 \mathrm{v}$.

17 «Testamento de Andrés Guauque, pintor», Tunja, 1625, AHRB, fondo Notaría 2, leg. 98 , f. 137 r. 
esposa pero sí tuvo un hijo natural llamado Juan ${ }^{18}$. Magdalena Corradine ubicó la casa de este artista a partir del censo de 1623, siendo curiosa la ubicación de esta por lindar con casas y solares de Juan Recuero ${ }^{19}$.

Otro de los nombres que destaca la historiadora Corradine Mora es el de Francisco Tenorio, a quien atribuye la realización del plano de Tunja de 1623, y como lo señala gracias a un pedimento de 1639 , calcula que el pintor habría nacido hacia 1597, pues contaba con 42 años en el momento que declarón ${ }^{20}$. Según su testamento ${ }^{21}$, era hijo de Alonso Hernández Tenorio y de Antonia de Castro, y contrajo matrimonio con Juana de Rojas, teniendo por hijos legítimos a María, Felipe, Ana, Francisco, Francisca y Joana. Quiso que su cuerpo fuera enterrado en la Iglesia parroquial de la Señora Santa Bárbara en la capilla de Nuestra Señora del Pilar de Zaragoza, demostrando la cercanía que tenía a este templo, pues como lo señaló M. Corradine fue sobrino natural del clérigo Antonio de Castro, patrono de la Ermita de Santa Bárbara, por lo que la suposición de esta historiadora de que podría haber sido el autor de las pinturas murales de este recinto tiene mucha validez ${ }^{22}$. En la redacción de su testamento dejó constancia que debía a unos indios de Samacá, cuyos nombres no recordaba, seis pesos que le dieron como señal de una obra (cuyo tema no aclara) que le pidieron hiciese y no acudieron a reclamarla, así como debía a unos indios de Soracá, cuyos nombres también había olvidado, cinco pesos poco más o menos por el trabajo que hicieron en la obra de la Iglesia de la Señora Santa Bárbara y en su casa, por lo que mandó se les pagara a satisfacción según el derecho. Se destaca nuevamente la presencia como testigo de Sebastián

18 «Testamento de Andrés Guauque, pintor», Tunja, 1625, AHRB, fondo Notaría 2, leg. 98 , ff. $135 \mathrm{r}-139 \mathrm{v}$.

19 Corradine, Vecinos y moradores..., 148.

20 Corradine, Vecinos y moradores..., 13.

21 "Testamento de Francisco Tenorio de Castro», Tunja, 1647, AHRB, fondo Notaría 2, leg. 118 , t. 1 , ff. $22 \mathrm{v}-24 \mathrm{v}$.

"Pedimento como testigo a Francisco Tenorio de Castro», Tunja, 1639, aunque en el lomo del tomo dice 1630, AHRB, fondo Archivo Histórico de Tunja, leg. 68, ff. $162 \mathrm{v}-163 \mathrm{r}$.

22 Corradine, Vecinos y moradores..., 14. 
de Ponte, lo que denota una relación óptima entre colegas del oficio.

Es Juana de $\operatorname{Rojas}^{23}$, esposa de Tenorio, quien en su testamento nos da información sobre las obras que tenían en su casa: Una imagen de nuestra Señora del Pilar de bulto de poco más de una tercia de alto puesta en un nicho dorado lo que resalta su devoción por esta advocación de la Virgen María-, tres niños «Jesuses», dos cuadros de una vara de alto, guarnecidos y dorados, uno de la Resurrección de nuestro Señor, y otro de Jesús nazareno, otro del Prendimiento de Cristo nuestro Señor, de vara y cuarta de alto, guarnecido y sin dorar, otro de san Antonio de la misma altura y de la misma guarnición sin dorar, uno de santa María Egipciaca del mismo tamaño, otro de la Adoración de los reyes sin guarnición con el mismo alto, tres países, cada uno de media vara de altura, ocho cuadritos de papel guarnecidos, otros dos, todos al temple. Destacó que por su hija María, casada con Diego Serrano, vecino de Vélez, dieron «tres cuadros y lo más que parezca por la carta de dote ${ }^{24}$, posiblemente, obras pintadas por su padre. Magdalena Corradine había subrayado que en este documento Juana hace mención al oficio de su marido, anotando:

[...] que se acuerda que el Padre Pedro Ramírez de Antequera envió a Francisco Tenorio una poca de plata que fueron cien pesos y no sabe ni se acuerda si fueron para en cuenta de la dicha casa o para el pago de la hechura de una imagen que le estaba haciendo el dicho Francisco Tenorio que estaba la hechura concertada en los dichos cien pesos $[\ldots]^{25}$.

Existen referencias de esta investigadora sobre otros pintores: Juan Bautista Castelo, pintor italiano, vecino de Tunja para 1620, casado con Catalina de Avendaño; Francisco García, casado con Juliana de la Cruz, padres de Bartolomé García o de la Cruz, Antonia, Miguel y Lázaro

23 «Testamento de Joana de Rojas», Tunja, 1660, AHRB, fondo Notaría 1, leg. 147, ff. $285 \mathrm{r}-286 \mathrm{v}$.

24 «Testamento de Joana de Rojas», Tunja, 1660, AHRB, fondo Notaría 1, leg. 147, f. $285 \mathrm{v}$.

25 Corradine, Vecinos y moradores..., 13 y 14. 
García; y Pedro de Aguirre Fadelano, autor del Calvario del Museo del Escribano Don Juan de Vargas de Tunja, firmado y con la leyenda: «Mandolo hacer el Secretario Álvaro González Sanguino, siendo Alcalde Ordinario de esta ciudad de Tunja, en el año $1616{ }^{26}$.

\section{Algunas notas sobre el oficio}

Los datos anteriores permiten concluir que no había una división entre los oficios de pintura, escultura, policromía y dorado como sí ocurría para la época en los sitios donde había gremios establecidos como Sevilla y México ${ }^{27}$, y que varios de estos artistas se dedicaron a todos. Ninguno de los pintores mencionados es denominado 'maestro' sino que aparecen como oficiales o simplemente se denominan 'pintor' o 'escultor de imaginería' sin reconocerse por ellos mismos o por otros como poseedores del grado máximo en dichas artes.

El desempeño del pintor y escultor Guauque, indio ladino de la Provincia de Quito, demuestra que su calidad de indígena no fue impedimento para dedicarse a tales oficios, y que fue aceptado como vecino de Tunja. Los testamentos de los demás pintores no entran en detalle sobre su origen, por lo que se podría suponer que habrían nacido en la Provincia, pues las personas oriundas en España solían decirlo al testar; posiblemente descendientes de mestizos o de familias de origen español con algunas generaciones ya nacidas en territorio neogranadino. Al parecer, los pintores de los pueblos de indios se dedicaron principalmente a la pintura de mantas.

La documentación no hace alusión específica a 'talleres' u 'oficinas' ni a espacios bien diferenciados de elaboración o tiendas para venta de obra, por lo que sus labores estarían integradas a sus casas. En los conciertos de aprendizaje y de compañía para trabajar, el oficial de más rango se comprometía

26 Corradine, Vecinos y moradores..., 127, 191 y 297.

27 Constantino Gañán Medina, Técnicas y evolución de la escultura policroma en Sevilla (Sevilla: Universidad de Sevilla, 1999), 34. Francisco del Barrio Lorenzot, Ordenanzas de gremios de la Nueva España (México: Dirección de talleres gráficos, 1920), 19-25. 
a dar morada al otro pintor, y la nota sobre arrendamiento de vivienda de la que hablan Recuero y Maldonado hace pensar en el traslado a otras poblaciones para ejecutar encargos. No se encuentran muchos conciertos de aprendizaje en las notarías tunjanas, y como taller familiar se destaca el de Juan Recuero que lega su conocimiento a sus hijos Sebastián y Juan.

En cuanto a la técnica, se nombran obras al óleo y al temple, y se sabe que en los murales usaban temples y pintura a la cal en seco; y sobre los materiales, el testimonio de Recuero en el pleito de Rojas contra Jove, destaca el uso de mantas de la marca como soporte, refiriéndose a las mantas de algodón que los indios de la Provincia de Tunja hacían tanto en sus casas como en obradores, siguiendo la tradición muisca y en algunos casos incluyendo cambios tecnológicos europeos ${ }^{28}$. De igual manera, Recuero nombraba el uso de oro en estas obras, lo que indica que la aplicación de hojillas de este metal no era labor exclusiva de un dorador como en Europa o Nueva España mandaban las ordenanzas. En otros documentos se habla simplemente de 'lienzos'.

En el registro de mercancías a Tierra Firme, del año 1607, constaba la existencia de cinco libras de cardenillo para ser entregadas a Diego Domínguez Melgarejo en Tunja ${ }^{29}$. Domínguez era mayordomo del Santísimo Sacramento, según lo indicó Sebastián de Ponte en su testamento ya citado anteriormente. Este mismo pigmento, el cardenillo, era usado por Guauque, así como el albayalde y el azul de Mérida ${ }^{30}$.

28 Claudia Marcela Vanegas Durán, La producción textil en el Nuevo Reino de Granada: Obrajes y tributación indígena en los Andes Centrales. Siglos XVI y XVII. Informe final presentado al Instituto Colombiano de Antropología e Historia - ICANH, Promoción a la Investigación en Historia Colonial (Bogotá: ICANH, 2007), acceso el 15 de junio de 2016, http://www.icanh.gov.co/?idcategoria=6505. Vargas Murcia, Laura Liliana, «De Nencatacoa a San Lucas: Mantas muiscas de algodón como soporte pictórico en el Nuevo Reino de Granada", Ucoarte. Revista de Teoría e Historia del Arte, $\mathrm{n}^{\circ}$ 4, (2015): 25-43.

29 «Registro de ida a Tierra Firme», Sevilla, 1607, Archivo General de Indias (AGI), fondo Contratación, 1151 A, n 5 , f. $414 \mathrm{v}$.

30 «Testamento de Andrés Guauque, pintor», Tunja, 1625, AHRB, fondo Notaría 2, leg. 98 , f. $136 \mathrm{v}$. 
También por el comercio indiano, estos pintores debieron ver estampas europeas que sirvieron como fuentes para sus obras, de las cuales se hallan registros como el de las cinco gruesas de estampas, a siete reales, que en 1584 llegaron a Cartagena de Indias en la nao «Nuestra Señora de la Candelaria" con Tunja como destino ${ }^{31}$. Las visitas a pueblos de indios permiten ver la entrada que tuvieron estas impresiones de papel a estas tierras; en 1602, en Busbanzá, el visitador de la provincia de Tunja, Luis Henríquez, apuntó dentro de la lista de bienes de la iglesia de este pueblo, una estampa de San Francisco en papel, 19 estampas de santos en papeles, la mayoría nuevas, y cuatro papeles grandes de tema histórico ${ }^{32}$. El mismo año, en la iglesia de Cerinza quince papeles de imágenes adornaban el $\operatorname{altar}^{33}$, mientras que en Soatá había tres papeles de figuras grandes sin especificar de qué tema trataban ${ }^{34}$. De igual manera, estas estampas aparecen en inventarios de civiles, vecinos de Tunja como la india quien en 1630 dejó registro en su testamento de 14 «retablos pequeños de papel guarnecidos de madera» de varios tamaños, los cuales dejó para vender o para dar al cura del pueblo de Soconzaque, de donde era natural ${ }^{35}$. Es de suponer que las ilustraciones grabadas de los libros que llegaron a las bibliotecas de clérigos y funcionarios de la Corona sirvieron de modelo para que éstos contrataran obras a los pintores, así, libros de emblemas, hagiografías, tratados, etc. ampliarían su repertorio visual ${ }^{36}$.

31 Pedro J. González-García, «El comercio de obras de arte de Sevilla a Hispanoamérica a fines del Siglo XVI (1583-1600)», (tesis de pregrado, Universidad de Sevilla, 1982), 299-302.

32 «Inventario de la iglesia de Busbanzá», Busbanzá, 1602, AGN, fondo Visitas Boyacá, leg. 18, f. 618v.

33 "Visita de la iglesia de Cerinza», Cerinza, 1602, AGN, fondo Visitas Boyacá, leg.19, f. 863r.

34 «Inventario de la iglesia de Soatá», Soatá, 1602, AGN, fondo Visitas Boyacá, leg.14, f. $495 \mathrm{v}$.

35 «Testamento de Isabel Ruiz», Tunja, 1630, AHRB, fondo Notaría 1, leg. 124, f. 73 v.

36 Por ejemplo, en la biblioteca del canónigo tunjano Fernando de Castro y Vargas, quien fue doctrinero de Turmequé y cura de la Catedral de Santafé, tuvo un interesante repertorio de este tipo de publicaciones, registradas en 1663 tras su muerte: Silva Allegoriarum Totius Sacrae Scripturae de Hieronymus Lauretus (primera edición: Barcelona, 1570), Hieroglipyca de Piero Valeriano, Emblemas morales de Juan de 


\section{La vida de los pintores en la sociedad tunjana}

Los testamentos permiten ver que además de sus labores en las artes, algunos poseían mulas y ovejas, estas últimas importantes en la producción de lana, material con el que se tejían mantas, además del algodón, y que constituían uno de los productos más representativos de la región, sirviendo como objeto de tributo o demora, de salario y de intercambio. Además de su uso como soporte, el aprecio que tuvieron las mantas tejidas en la Provincia de Tunja como mercancíamoneda, se capta en ciertos apartes de los documentos de estos pintores en los que son objeto de deuda o de pago ${ }^{37}$.

Estos pintores pertenecieron a cofradías de iglesias tunjanas, a las que, a juzgar por las capellanías que tuvieron y los censos, estuvieron fuertemente comprometidos, no solo religiosa sino económicamente. Además de la citada capellanía de Andrés Guauque en la Hermandad de la Soledad de la Iglesia Mayor, podemos citar que en 1599, Juan Recuero y su mujer María de Ponte renovaron un censo con la cofradía de Nuestra Señora de la Concepción, el cual se había hecho por cincuenta pesos de 13 quilates por su casa, hipoteca que databa de 1581, siendo su fiador Pedro Chinchilla ${ }^{38}$.

Horozco y Covarrubias (primera edición: Segovia, 1589), Idea de un Príncipe Político Christiano representada en cien empresas de Diego Saavedra Fajardo (primera edición: Mónaco, 1640), Philosophia secreta de Juan Pérez de Moya (primera edición, 1585) y Emblematum liber de Andrea Alciato (primera edición: Augsburgo, 1531), que aunque algunas quizás fueron adquiridas a su paso por Santafé, dan idea de las inquietudes intelectuales que tenía desde sus épocas de juventud.

$37 \quad$ El pintor y escultor Guauque declaró que Lucas indio natural de Guatavita mantenía en su poder una manta colorada de Chivatá de maures, y seis reales de a ocho, suyos, que se los dio Alonso Esteban como un cobro en Pamplona, y hacían parte de sus bienes. En: «Testamento de Andrés Guauque, pintor», Tunja, 1625, AHRB, fondo Notaría 2, leg. 98, ff. 136rv.

El pintor Juan Recuero declaró que Miguel Gómez, zapatero, le pidió que le pagara un vale de cantidad de pesos que era de Sebastián de Mojica Buitrón, pero afirmaba ya haberlo pagado y no deber nada, y declaraba que como no sabía leer ni escribir, y por excusar su letra y por haber sacado mandamientos contra él, le había pagado ocho pesos con una manta colorada de maures y tres en un caballo. En: «Testamento de Juan Recuero de Céspedes», Tunja, 1630, AHRB, fondo Notaría 2, leg. 103, ff. $65 r-68$.

38 «Censo de Juan Recuero y María de Ponte», Tunja, 1599, AHRB, fondo Notaría 2 , leg. 65 , ff. $228 \mathrm{r}-230$ r. 
Estos oficiales son nombrados en manuscritos por varias causas, además de los conciertos de sus oficios: dotes, obligaciones, testimonios, censos, compras y ventas, en las que se ven contactos que tienen con personajes de índole variada de la ciudad, desde mulatos esclavos a capitanes, y que en ocasiones ofrecen datos interesantes. Ejemplos de ello son: el testimonio de Tenorio sobre Gaspar de Morales y Juan de Betancur ${ }^{39}$, que permitió calcular el año de nacimiento del pintor; y el testimonio de Sebastián de Ponte Recuero sobre Mónica Pérez de Leyton, mestiza, hija del español Hernando de Leyton y de una india llamada Leonor, y madre de un joven zapatero mestizo de nombre Tomás González, manuscrito de importancia porque en él, Sebastián de Ponte dijo tener 25 años ${ }^{40}$ lo que indicaría que habría nacido hacia 1607 . Como se vio anteriormente en otros casos notariales este pintor sirvió de testigo llamado por compañeros de su oficio, lo que hace suponer que aunque no hubo un gremio constituido, sí había entre ellos una disposición de colaboración, así como con otros artesanos de la ciudad.

En cuanto a la producción de obras se ve especialmente la realización de estas por encargo, aunque se observa que los compradores de imágenes religiosas también podían adquirirlas a través de mercaderes, tal como se observa en la obligación de pago en la que en 1618, el capitán Juan de Contreras Arellano, vecino de Tunja se comprometía a pagar al mercader Diego Jiménez de Medina 2.300 pesos de plata corriente, por varias mercancías, entre ellas: un tabernáculo dorado con una imagen de Nuestra Señora de bulto con dos coronas de plata engastadas en piedras y cuatro candeleros grandes con sus arandelas doradas, lo que valía 100 pesos de plata, y cuatro lienzos de vara y media a cien pesos de plata, uno de Santiago, otro de Santa Ana y la Virgen, el otro de San Bartolomé en el martirio y el otro de Cristo en la columna,

39 «Pedimento como testigo a Francisco Tenorio de Castro», Tunja, 1639, aunque en el lomo del tomo dice 1630, AHRB, fondo Archivo Histórico de Tunja, leg. 68, ff. $162 \mathrm{v}-163 \mathrm{r}$.

40 «Sebastián Ponte Recuero, testigo», Tunja, 1632, aunque en el tomo indica 1622, AHRB, fondo Notaría 2, t. 58, ff. 427v-428v. 
guarnecidos y dorados ${ }^{41}$. Estas pinturas podían haber sido hechas tanto por pintores locales como por europeos que enviaban sus lienzos a través de la Carrera de Indias. Los temas religiosos predominaron, aunque aparecen notas sobre pinturas de tema civil como lo son los 'países'.

Las casas que habitaban estos pintores se encuentran ubicadas en el Anexo VIII de Vecinos y moradores de Tunja 1620 - 162342: Francisco Tenorio de Castro (n $\left.{ }^{\circ} 23\right)$, Francisco García ( $\left.n^{\circ} 70\right)$, Andrés Guauque ( $n^{\circ} 93$ bis), Juan Recuero $\left(n^{\circ}\right.$ 94), Juan Bautista Castelo ( $\left.n^{\circ} 307\right)$ y Lorenzo de Aponte, quien además de ser espadero, platero y pavonador, era dorador $\left(\mathrm{n}^{\circ}\right.$ 88). Para el año del censo, Juan de Rojas ya había fallecido, pero sobrevivía su esposa Isabel Arias Rincón ( ${ }^{\circ} 191$ bis).

En el censo de 1620, Francisco García vivía en compañía de su esposa Juliana y sus hijos Bartolomé, Antonia, Miguel y Lázaro, y una india a su servicio; en la casa de Juan Recuero se registraron su esposa María de Ponte, sus hijos Margarita, Francisca y su esposo Francisco García de Tineo e hijo José Gregorio Tineo, Lorenza, José, Sebastián, Bartolomé, Agustina y María. Además, Margarita de la Mota, medio hermana de la mujer de Recuero, un hombre llamado Juan Vicente y dos indias al servicio de la casa; Guauque se censó en una casa en donde vivía una pareja de indios que tenía un hijo; Castelo, para esa fecha vivía solamente con una mujer a su servicio, registrada como 'morena' ${ }^{43}$.

En lo que respecta a las ganancias económicas que podían tener los pintores con su oficio, se puede ver cómo la situación de un pintor a otro varía, también dependiendo de los diferentes momentos de su vida. En los contratos y en los testamentos se hallan casos de obras excelentemente

41 «Obligación del capitán Juan Contreras Arellano», Tunja, 1618, AHRB, fondo Notaría 2, leg. 59, ff. 387r.-389r.

42 Corradine, Vecinos y moradores..., Anexo VIII, «El plano de Tunja de 1623, sobre el cual se colocan los números de las casas que se relacionan con el Censo de 1620» dibujó: Arq. Mery González Terán, dirigió: Historiadora Magdalena Corradine.

43 Corradine, Vecinos y moradores..., 137, 148, 162 y 289. 
remuneradas ${ }^{44}$, pero también demandas por impagos, pintores dueños de decenas de cabezas de ganado y a la vez con deudas, artistas sin hijos como los que tuvieron una gran familia que mantener, por lo que sería imposible generalizar la condición que tuvieron. Sin embargo, sí es posible ver que los pintores, escultores y doradores contaron constantemente con encargos de obra, casi siempre testando con pinturas o esculturas por entregar.

\section{Conclusiones}

La importancia política y económica que adquirió Tunja como ciudad y como Provincia del Nuevo Reino de Granada en la segunda mitad del siglo XVI brindó condiciones propicias tanto para el encargo de obras a España como atractivas para la llegada de artistas europeos como los citados Medoro y Castelo, y posteriormente fue llamativo el aprendizaje del oficio por parte de artífices locales. La necesidad de imágenes para los espacios civiles y eclesiales de la naciente ciudad, ya fuera con fines devocionales, ornamentales o de reconocimiento social generó una demanda de pintores, escultores y doradores. Los pintores tunjanos a través del contacto con obras y maestros europeos fueron conociendo los materiales, las técnicas y las iconografías, realizando así la producción que surtiría la ciudad y los pueblos de indios de la Provincia que hacía relativamente poco se habían fundado. La compra de imaginería religiosa por parte de los indios demuestra la integración que ya para el siglo XVII tenía este sector de la población, quienes por su propia iniciativa la costeaban.

Aunque no se hallan menciones a gremios ni ordenanzas, sí hay conciertos de índole legal para establecer obligaciones, derechos y deberes tanto en la enseñanza y el aprendizaje

44 Por ejemplo el pleito de Juan de Rojas y Antonio de Jove por la deuda de pinturas tasadas en 400 pesos de oro corriente, realizadas en alrededor de dos meses en el año de 1582 , cuando por esta época un indio ganaba 2,5 pesos de oro al mes en una mina. Ver: Vargas Murcia, Del pincel..., 48. O el pago de 400 pesos de oro de 20 quilates a Angelino Medoro en 1598 por sus trabajos en la Capilla de los Mancipe, comparados con los 4 pesos diarios de 20 quilates que ganaba un oidor por visita en 1599. Ver: Laura Liliana Vargas Murcia, «Del arte de pintores» en Catálogo Museo Colonial. Volumen I: Pintura (Bogotá: Ministerio de Cultura, 2016), 67-83. 
como en el contrato y ejecución de obras. Entre los pintores estudiados no se encuentra especificado en los manuscritos el grado de 'maestro', en cambio sí se denominan varios de ellos 'oficiales' y los jóvenes a su cargo eran reconocidos como 'aprendices'. El dato del analfabetismo de Juan Recuero sugiere un predominante componente oral en la enseñanza, aunque no se debe generalizar que los artistas o artesanos no supieran leer y escribir. Los testamentos de estos artistas no revelan la presencia de tratados de pintura o libros con imágenes entre sus propiedades, lo que podría hacer pensar en que el contacto con ciertas iconografías se hizo a través de las bibliotecas de los patrocinadores de las obras o estampas sueltas.

Los documentos consultados permiten plantear una ubicación aproximada de los pintores en el tiempo. Los siguientes serían los años de nacimiento que se pueden inferir: Juan Recuero (1566), Mateo Maldonado (1568 - 1571), Francisco Tenorio de Castro (1597) y Sebastián de Ponte Recuero (1607). El año del testamento no siempre corresponde al de la muerte pero sí indica que para ese momento el declarante estaba vivo; al respecto se tiene que Andrés Guauque testó en 1625, Juan Recuero de Céspedes en 1630, Sebastián de Ponte en 1633 y Francisco Tenorio de Castro en 1647. Y aunque la ausencia de firmas dificulta la identificación de obras de cada artista se podrían tipificar características técnicas y estilísticas que permitan agruparlas para empezar a datar y diferenciar las pinturas y esculturas hechas en Tunja y las provenientes de otras zonas, y en algunos casos ubicar la imaginería perteneciente a iglesias boyacenses, nombradas en documentos que sí dan el nombre de su autor.

Apéndice

«Compañía entre Juan Recuero y Mateo Maldonado para ambos trabajar como pintores" (Tunja, 15 de diciembre de 1593), AHRB, Notaría Segunda, legajo 54, ff. 199r - 201r. 
[f. 199 r.] Hacen compañía Juan Recuero, vecino de esta ciudad y Mateo Maldonado en que por tiempo y espacio de dos años que corren desde hoy día el dicho Mateo Maldonado ha de estar en compañía del dicho Recuero y en el dicho tiempo trabajar al oficio de pintor, lo que fuere necesario y le ordenare el dicho Recuero y lo que se ganare, sacadas costas, se ha de partir entre ambos en esta manera: que el dicho Mateo Maldonado ha de llevar el tercio de lo que se ganare en obra de pintura y que lo que se hiciere en bultos el quinto, y lo demás ha de haber el dicho Juan Recuero no se ha de poder deshacer la compañía durante el dicho tiempo, so pena de 200 pesos de oro corrientes para la cámara de su majestad y parte obediente por mitad. Oblíganse en forma el dicho Maldonado, jura la menoría por ser mayor de 22 años y menor de veinte y cinco.

Sepancuantos esta carta de concierto y compañía vieren como nos, Juan Recuero, vecino desta ciudad de Tunja del Nuevo Reino de Granada de las Indias, oficial que soy del oficio de pintor y Mateo Maldonado morador en esta dicha ciudad y oficial que ansí mismo soy del dicho oficio, otorgamos y conocemos por esta presente carta que hacemos concierto y compañía en tal manera que por el tiempo de dos años cumplidos primeros siguientes, yo el dicho Mateo Maldonado tengo de estar y asistir en compañía de vos el dicho Juan Recuero y sin hacer falta ni falla ninguna tengo de trabajar a el dicho oficial en todas las obras de pintura de pincel y guarnecerla de bulto y asentar colores, dorar y labrar en lienzos y en las otras y demás cosas anexas a el dicho oficio que por vos, el dicho Juan Recuero, me fuere ordenado y mandado sin exceptación [sic] ni escusa ninguna, todo lo que más pudiere, y ansí mismo yo, el dicho Juan Recuero, tengo de trabajar al dicho oficio durante el dicho tiempo en las obras que se ofrecieren ocupando al dicho Maldonado en ellas según y como de [f. 199 v.] suso se contiene y declara y todos los pesos de oro y otras cualesquier cosas que durante el dicho tiempo se fueren ganando y adquiriendo con el trabajo del dicho oficio se han de partir entre nos en las especies que se ganaren y adquirieren en esta manera: que se han de sacar del monto de ganancias principal que todas las obras y labores que se hubieren labrado y labraren montaren todos los gastos de colores, lienzos y otros aderezos que se hubieren gastado en labor y beneficio dello y ansí mismo los gastos de comida y alquiler de casa y los que con nuestras personas hiciéremos en cuanto a la dicha comida, y lo que sacados los dichos gastos 
quedare se ha de apartar lo que hubiere ganado de lo que fuere obra de pincel y pintura, que es postura y condición haber de ser y entenderse la tal obra distinta de la de bulto, en tal manera que el dicho Juan Recuero ha de haber y llevar dello de tres partes principales que dello se ha de hacer, dos, y el dicho Mateo Maldonado la tercera restante y lo que quedare y quede quitados costas y gastos de la dicha obra de bultos, que se entiende dorados, encarnaciones y otras obras gruesas que se labraren en bulto, se ha de partir [f. 200 r.] entre nos haciendo de lo que en las dichas obras de bulto se ganare cinco partes principales y dellas las cuatro ha de haber y llevar el dicho Juan Recuero y la otra quinta restante el dicho Mateo Maldonado y es condición que de todas las dichas obras y ganancias haber y se ha de tener cuenta y razón para líquidamente separar lo que de cada cosa se hubiere ganado y ganare, y ansí mismo que de la parte que a cualquier por la orden dicha perteneciere y hubiere de haber se quite y descuente los gastos de vestidos, calzados y otras cualesquier cosas que sacare y tomare durante el dicho tiempo desta compañía y lo que los dichos gastos que ansí hiciere de los que dichos son, montaren aquello mismo, haya y lleve menos en la dicha parte que hubiere de haber, todo lo cual que dicho es, ansí pagaremos y cumpliremos durante el dicho tiempo de los dichos dos años cumplidos primeros siguientes hasta que sean cumplidos, sin que por ninguna vía, causa ni razón que sea no nos podamos quitar si [sic] salir por ir ni venir contra ello, so pena de que demás y allende de que queremos y consentimos que todas y cualesquier justicias de su majestad de cualesquier partes que sean nos compelan y apremien por todo rigor a lo ansí cumplir y haber por firme la parte que demás contra ello fuere o pasare y lo intentare caiga e incurra en pena de doscientos pesos de buen oro de veinte quilates cada un peso, la mitad dellos para la cámara del rey nuestro señor y la otra mitad para la parte obediente para la parte [f. 200 v.] obediente ${ }^{45}$ que por ello estuviere y pasare y lo cumplire, la cual dicha cantidad, la parte que contra ello fuere o pasar quisiere la ha de exhibir antes que lo tal intente o que le sea por la otra obediente pedido y en el inter que no lo hiciere no sea sobre ello oído ni admitido en juicio y la dicha pena pagada o no o graciosamente remitida que esta escritura y lo en ella contenido sea firme y valga, para lo cual ansí cumplir, pagar y haber por firme obligamos por lo que a cada uno toca

45 Repite «parte obediente». 
nuestras personas y bienes muebles y raíces habidos y por haber y damos poder cumplido a todas y cualesquier justicias y jueces del rey nuestro señor de cualesquier partes que sean donde y ante quien la paga y cumplimiento de lo que dicho es nos fuere pedido y demandado, al fuero y jurisdicción de las cuales y de cada una de ellas nos obligamos y sometemos con las dichas nuestras personas y bienes y renunciamos nuestro propio fuero, jurisdicción, domicilio y vecindad y la ley si convenerit de jurisdicione omyum judicun [sic] como en ella se contiene, para que con todos los remedios y rigores del derecho nos compelan y apremien como sentencia definitiva de juez competente pasada en cosa juzgada, acerca de lo cual renunciamos todas y cualesquier leyes de nuestro favor que en este caso tratan para no nos aprovechar dellas y en especial renunciamos la ley y regla del derecho en que dice que general renunciación de leyes hecha no vala, y yo el dicho Mateo de Castro $^{46}$, por ser como soy menor de veinte y cinco años y mayor de veinte y uno, juro y prometo [f. 201 r.] por Dios nuestro señor y por Santa María su madre, por las palabras de los santos cuatro evangelios sobre la señal de la cruz en forma de derecho de pagar, cumplir y haber por firme esta carta de compañía y todo lo en ella contenido y de no ir ni pasar contra ella por decir que para la hacer y otorgar fui leso y engañado ni atemorizado por el dicho Juan Recuero ni por otra persona, ni que dolo o engaño dio causa a la hacer, por cuanto declaro que la hago y otorgo de mi libre y espontánea voluntad sin premia ni inducimiento alguno y que soy sabedor del hecho y de lo que en este caso hacer me convino y certificado de mi derecho, y que el hacer y otorgar esta dicha escritura de compañía es en mi utilidad y provecho respecto de que además de que en ella soy interesado y seré pagado de lo que por mi trabajo pudiera haber, el dicho Juan Recuero me enseñará y con él más me industriaré en el dicho oficio de pintor, con que seré muy aprovechado, mayormente que el dicho Juan Recuero de su mismo caudal y hacienda pone de presente los materiales y gastos para el beneficio de la dicha pintura, y cumpliré y habré por firme lo que dicho es, so pena de perjurio infame y de caer en las otras penas en que caen los que quebrantan semejantes juramentos solemnes como este, so cargo del cual prometo de no pedir contra él absolución ni relajación y caso de que de propio motivo me sea concedido no usaré del

46 Aparece el apellido 'Castro', quizá por equivocación del escribano o el pintor se llamaba Mateo Maldonado de Castro. 
y lo renuncio y aparto de mi favor. En testimonio de lo cual otorgamos la presente carta en la manera que dicha es ante el presente escribano y testigos. En la ciudad de Tunja a quince días del mes de diciembre de mil y quinientos y noventa y tres años. Testigos: Sebastián de Ponte y Francisco de Velandia y Francisco Verdugo residentes en esta ciudad y los otorgantes que conozco lo firmaron de sus nombres:

Juan Recuero ${ }^{47}$

Mateo Maldonado

Ante mí: Diego Solórzano, escribano.

\section{Fuentes documentales}

Archivo General de la Nación (AGN). Bogotá - Colombia. Sección Colonia, fondos Residencias de Boyacá y Visitas Boyacá.

Archivo Histórico Regional de Boyacá (AHRB). Tunja - Colombia. Sección Protocolos Notariales. Fondos Notaría 1, Notaría 2 y Archivo Histórico de Tunja.

Archivo General de Indias (AGI), Sevilla - España, Fondo Casa de Contratación.

\section{Bibliografía}

Corradine Mora, Magdalena. Vecinos y moradores de Tunja 16201623. Tunja: Consejo editorial de autores boyacenses, 2009.

Del Barrio Lorenzot, Francisco. Ordenanzas de gremios de la Nueva España. México: Dirección de talleres gráficos, 1920.

Gañán Medina, Constantino. Técnicas y evolución de la escultura policroma en Sevilla. Sevilla: Universidad de Sevilla, 1999.

Gila Medina, Lázaro y Francisco J. Herrera García. «Escultores y esculturas en el Reino de la Nueva Granada (Colombia)». En La escultura del primer naturalismo en Andalucía e Hispanoamérica, coordinado por Lázaro Gila Medina, Madrid: Ministerio de Ciencia e Innovación, 2010.

47 Como se dijo anteriormente, Juan Recuero no sabía firmar en el concierto de aprendizaje de 1587; en este concierto con Maldonado firmó con una mala caligrafía. 
González-García, Pedro J. «El comercio de obras de arte de Sevilla a Hispanoamérica a fines del Siglo XVI (1583-1600)». Tesis de pregrado, Universidad de Sevilla, 1982.

Morales Folguera, José Miguel. Tunja, Atenas del Renacimiento en el Nuevo Reino de Granada. Málaga: Universidad de Málaga, 1998.

Sebastián, Santiago. Estudios sobre el arte y la arquitectura coloniales en Colombia. Bogotá: Corporación La Candelaria y Convenio Andrés Bello, 2006.

Vanegas Durán, Claudia Marcela. La producción textil en el Nuevo Reino de Granada: Obrajes y tributación indigena en los Andes Centrales. Siglos XVI y XVII. Informe final presentado al Instituto Colombiano de Antropología e Historia - ICANH, Promoción a la Investigación en Historia Colonial (Bogotá: ICANH, 2007), acceso el 15 de junio de 2016, http://www. icanh.gov.co/?idcategoria $=6505$.

Vargas Murcia, Laura Liliana. Del pincel al papel: Fuentes para el estudio de la pintura en el Nuevo Reino de Granada (15521813). Bogotá: Instituto Colombiano de Antropología e Historia ICANH, 2012.

Vargas Murcia, Laura Liliana. «De Nencatacoa a San Lucas: Mantas muiscas de algodón como soporte pictórico en el Nuevo Reino de Granada». Ucoarte. Revista de Teoría e Historia del Arte, $\mathrm{n}^{\circ}$ 4, (2015): 25-43.

Vargas Murcia. Laura Liliana, «Del arte de pintores». En Catálogo Museo Colonial. Volumen I: Pintura. Bogotá: Ministerio de Cultura, 2016.

\section{Citar este artículo:}

Vargas Murcia, Laura Liliana. «Pintores en el esplendor de Tunja: nombres de artífices para salir del anonimato (siglos XVI y XVII)». Historia Y MEMORIA, $\mathrm{n}^{\circ} 15$ (2017): 49-72. DOI: https://doi.org/10.19053/20275137.n15.2017.5538 